\title{
Carpal tunnel syndrome in vibration disease
}

\author{
K Koskimies, M Färkkilä, I Pyykkö, V Jäntti, S Aatola, J Starck, R Inaba
}

\begin{abstract}
The presence of carpal tunnel syndrome (CTS) in 125 forestry workers with exposure to vibration was examined clinically by electromyography and by determining vibration detection thresholds. Numbness of the hands was present in $43 \%$, history of diminished hand muscle force in $15 \%$, and Raynaud's phenomenon in $27 \%$. The muscle weakness correlated significantly with motor nerve conduction velocity in the median nerve in both hands. In 25 forestry workers CTS was diagnosed. The condition was bilateral in $\mathbf{4 8 \%}$; otherwise it was more common on the right side. Fifteen patients were referred for surgery but because of spontaneous recovery or refusal by the patients only five underwent surgery; of these four improved. The motor conduction velocity of the ulnar nerve was decreased among patients with CTS supporting the idea that entrapment neuropathies in the hands may be due to tissue swelling caused by vibration at work. Total exposure time to vibration correlated with the decrease in motor conduction velocity in the ulnar nerve.
\end{abstract}

Prolonged exposure to hand-arm vibration may cause peripheral neuropathy ${ }^{12}$ with symptoms such as numbness and pain in the hands, nocturnal paresthesia, and muscle weakness. ${ }^{34}$ The vibration induced symptoms in the peripheral nerves may arise from vascular insufficiency of the minute nerve terminals, ${ }^{56}$ by damage to the non-specific myelin sheath, ${ }^{1}$ by intraneural oedema leading to secondary nerve degeneration, ${ }^{7}$ or by isolated nerve damage due to entrapment. ${ }^{8}$

\footnotetext{
Institute of Occupational Health, Helsinki, Finland K Koskimies, J Starck, R Inaba

Department of Neurology, University Hospital of Helsinki, Helsinki

$M$ Färkkilä

Department of Otolaryngology, University Hospital of Helsinki, Helsinki

I Pyykkö

Department of Clinical Neurophysiology, University Central Hospital, Turku

V Jäntti

Technical Research Centre, Espoo

S Aatola
}

Heavy, repetitive work with exposure to hand-arm vibration increases the risk of carpal tunnel syndrome (CTS $)^{9-11}$ the symptoms of which resemble those described in association with exposure to handarm vibration. Lucas reported nerve damage in the median or ulnar nerve in workers exposed to handarm vibration. ${ }^{8}$ In a detailed analysis he linked the peripheral neuropathies to different entrapment conditions in the cervical, elbow, or wrist areas. He reported the prevalence of nerve damage due to carpal tunnel entrapment to be as high as $32.8 \%$ in some groups.

The purpose of the present study was to examine neurological symptoms, electromyographic (EMG) findings, and the vibrotactile perception threshold of professional forestry workers to measure the prevalence of CTS and other non-specific effects caused by vibration in the peripheral nerves of the hands.

\section{Subjects and methods}

The investigation was carried out in Suomussalmi parish in north eastern Finland as part of a compulsory health examination in 1983. Altogether 217 forestry workers were examined. We have followed up these workers in a longitudinal study since $1972 .{ }^{+1213}$ The workers were all employed by the National Board of Forestry and only forestry workers who had used a chain saw for 500 hours during the past three consecutive years were included. ${ }^{4}$ The mean duration of exposure to chain saw vibration was 16000 (SD 4400); the percentage distribution of exposure time is shown in fig 1 . The mean age of the forestry workers was 43.6 years (SD 8.3).

Medical history was recorded and a physical examination carried out. ${ }^{13}$ This consisted of routine examination of general health, verification of occupational history, vibrotactile perception measurement, measurement of hearing, and performance of a cold provocation test as necessary. Men with primary Raynaud's disease, rheumatoid arthritis, diabetes, or positive urine glucose slide test results were excluded from the study.

\section{NEUROLOGICAL EXAMINATION}

A history of symptoms in the hands was carefully taken, especially symptoms linked to CTS (numbness of the fingers innervated by the median nerve, paraesthaesias, especially at night, waking up times in the night, and other aggravating symptoms). 


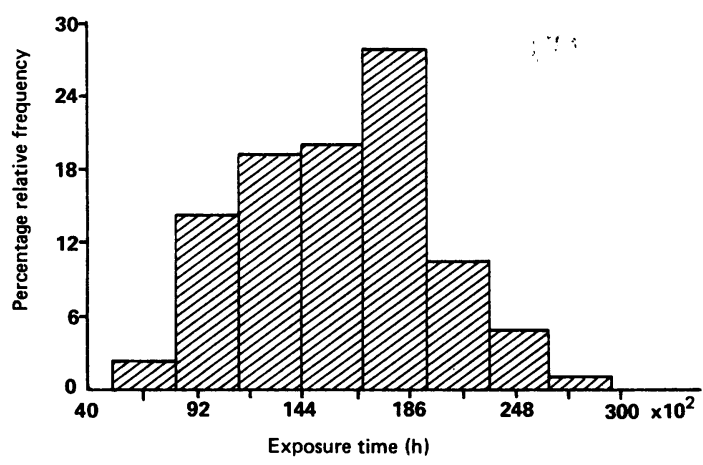

Figure 1 Percentage of distribution of the forestry workers according to vibration exposure time.

Furthermore, the subjects were asked if they had had these symptoms during the past 10-20 years.

All workers attended a clinical neurological examination performed by the same neurologist (MF). Subjective symptoms were classified to be present or not and Phalen's and Tinell's tests were performed. ${ }^{14}$

\section{VIBROTACTILE PERCEPTION MEASUREMENTS}

Vibration detection threshold at frequencies of 63 , 125 , and $250 \mathrm{~Hz}$ were determined with a method described previously. ${ }^{15}$

\section{NEUROPHYSIOLOGICAL EXAMINATION}

A total of 125 professional forestry workers were randomly selected from this group for detailed EMG. Neurophysiological examination included the measurements of sensory and motor nerve conduction velocities (NCV) of the median and ulnar nerves in both hands. Sensory NCV was measured in both nerves of the third finger, stimulating at the wrist. When necessary, sensory NCV were measured from the wrist to other fingers. The response was recorded with a Disa (13L 22) surface electrode, which has two saline soaked felt pads placed $2 \mathrm{~cm}$ apart. Measurements were made on the screen of a portable Medelec Ms 7 electromyograph. Motor NCVs in the median and ulnar nerves were measured by stimulating at the wrist (for measurements of distal motor latencies) and at the elbow or above the sulcus nervi. ulnaris. The response was recorded with a Disa surface electrode over the thenar and first dorsal interosseus muscles. Measurements were made by VJ. The temperature of both palms was controlled before measurements were taken.

A diagnosis of CTS was based on a typical history of numbness especially at night, exclusion of other conditions, results of Tinell's and Phalen's tests, and findings in the sensory and motor nerve EMG studies. CTS was classified $0=$ no CTS, $1=$ mild, $2=$ moderate, and $3=$ severe. In a further analysis the subjects were divided into two groups: those with clear or probable CTS and those without CTS. After two years a questionnaire was sent to 15 patients with CTS who had been referred to a surgeon and the results of the consultation were then analysed.

\section{STATISTICS}

The differences in NCVs and other variables between these groups were tested with Student's $t$ test. The correlations were calculated by using linear regression analysis.

\section{Results}

SUBJECTIVE SYMPTOMS

Numbness of the hands was present in $\mathbf{5 4}$ forestry workers $(43 \%)$. A history of diminished hand muscle force was present in $19(15 \%)$. A present or past history of vibration induced white finger (VWF) was reported by 34 of the forestry workers $(27 \%)$. Seven men still have VWF and the prevalence of active VWF was thus $5 \%$.

The weakness of the hand muscles correlated significantly with motor NCV of the median nerve in both hands (right hand: $r=-0.322, p=0.001$, left hand: $r=-0.224, p=0.01)$. A positive correlation was found between weakness of hand muscle force and numbness $(r=0.280, p=0.01)$. Hand muscle weakness did not correlate with VWF $(r=-0.015$, $\mathrm{p}=\mathrm{ns}$ ). Alcohol consumption had no correlation with numbness $(r=0 \cdot 147, p=n s)$. VWF did not correlate with reduced motor or sensory NCV in either the median or ulnar nerves ( $\mathrm{r}$ values between 0.029$0 \cdot 174, p=n s)$.

\section{NEUROPHYSIOLOGICAL FINDINGS}

Table 1 shows the mean values of motor and sensory $\mathrm{NCV}$ and distal latencies for the ulnar and median nerves in both hands. We found a correlation between exposure time and motor NCV in the median nerve of the right hand $(r=-0.274, p=0.01)$. The correlation in the left hand was not statistically significant $(r=-0 \cdot 123, p=n s)$. Exposure time was correlated with motor NCV in the ulnar nerve in both hands (right hand: $r=-0.259, p=0.05$, left hand: $\mathrm{r}=-0.389, \mathrm{p}=<0.001$ ) (fig 2). Distal latencies in the median nerve correlated with exposure time (right hand: $r=0.172, p=0.05$, left hand: $r=0.214$, $p=0.05)$. No correlation was found with exposure and distal latencies for the ulnar nerve.

\section{VIBROTACTILE PERCEPTION}

Vibrotactile detection threshold correlated with a history of hand muscle weakness but not with numbness or with motor NCV in the median and ulnar nerves.

\section{CARPAL TUNNEL SYNDROME}

In 25 forestry workers $\left(20^{\circ}\right)$ clinical CTS was 
diagnosed. Of these men, $12(48 \%)$ had bilateral CTS. Right sided CTS were found in 10 men and left sided in three. Nevertheless, the CTS of the right hand, in general based on conduction velocities in the median nerve, was milder than in the left hand. Of the 22 men with right sided CTS, 20 were classified as mild cases and two as moderate. Of the 15 subjects with left sided CTS, 10 were classified as mild, three as moderate, and two as severe. Table 2 shows conduction velocities and distal latencies (mean and SD) for the median and ulnar nerves in the CTS and no CTS groups. Numbness correlated with sensory NCV of the median nerve (right hand: $r=0.679$, $p<0.001$, left hand: $r=0.530, p<0.01)$. Exposure time correlated with motor NCV in the left ulnar nerve $(r=-0.519, p<0.01)$ but not the right $(\mathrm{r}=-0.315, \mathrm{p}=\mathrm{ns})$. In subjects with CTS we found a correlation with VWF and sensory NCV in both median nerves (right: $r=0.598, p<0.01$, left: $r=0.586, p<0.01)$. CTS correlated significantly with the increase of the vibrotactile threshold in the left hand $(n=15)$.

\section{OPERATED PATIENTS}

Most of the 25 subjects with CTS, however, had mild symptoms at rest, despite severe reduction of sensory NCV of the median nerve and had been improving during the course of the follow up. After neurological examination, however, 15 were referred for surgery.
Table 1 Motor (MCV) and sensory (SCV) nerve conduction velocities and motor distal latencies ( $D L$ ) (mean and $S D$ ) of 125 forestry workers exposed to vibration

\begin{tabular}{lrr}
\hline & Right hand & Left hand \\
\hline Median nerve: & & \\
MCV (m/s) & $53 \cdot 6 \pm 4 \cdot 0$ & $54 \cdot 6 \pm 4 \cdot 5$ \\
DL (ms) & $3 \cdot 9 \pm 0 \cdot 4$ & $3 \cdot 9 \pm 0 \cdot 6$ \\
SCV $(\mathrm{m} / \mathrm{s})$ & $43 \cdot 0 \pm 5 \cdot 8$ & $45 \cdot 3 \pm 5 \cdot 4$ \\
Ulnar nerve: & & \\
MCV $(\mathrm{m} / \mathrm{s})$ & $54 \cdot 6 \pm 4 \cdot 1$ & $56 \cdot 2 \pm 4 \cdot 1$ \\
DL $(\mathrm{ms})$ & $4 \cdot 3 \pm 0 \cdot 4$ & $4 \cdot 5 \pm 0 \cdot 5$ \\
SCV $(\mathrm{m} / \mathrm{s})$ & $48 \cdot 1 \pm 4 \cdot 5$ & $49 \cdot 0 \pm 3 \cdot 8$ \\
\hline
\end{tabular}

Of these, one was considered atypical for CTS and was regarded as having a vibration induced nonentrapment neuropathy, three improved spontaneously during the period, two refused surgery, and two had retired and considered the symptoms less severe since their daily work activities ceased. Thus only five underwent surgery, one on the right side, two on the left, and two bilaterally. Four reported good recovery and experienced no more symptoms. One had had no relief of symptoms after the operation when questioned two years later.

\section{Discussion}

CARPAL TUNNEL SYNDROME

The diagnosis of CTS must be based on symptoms,

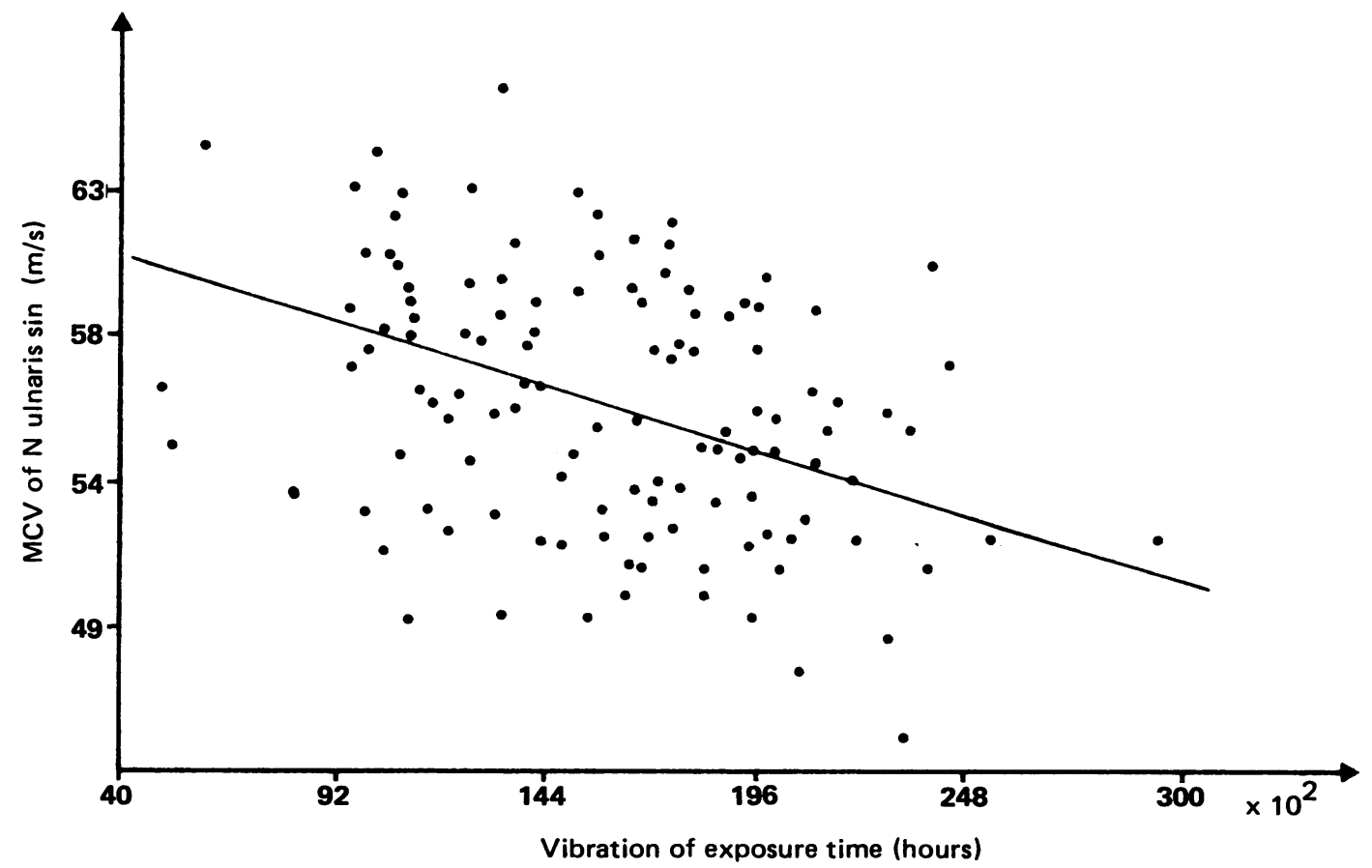

Figure 2 Correlation of motor conduction velocity in left hand (MCV) of ulnar nerve and vibration exposure time. 
Table 2 Motor (MCV) and sensory (SCV) nerve conduction velocities and motor distal latencies $(D L)$ on median and ulnar nerve in right and left hand of forest workers with carpal tunnel syndrome (CTS) and without $C T S$. The statistical analysis is based on two sample t test and $t$ values are seen in the table (means and SD)

\begin{tabular}{|c|c|c|c|}
\hline No & $\begin{array}{l}\text { CTS } \\
(n=25)\end{array}$ & $\begin{array}{l}\text { No CTS } \\
(n=100)\end{array}$ & $t$ \\
\hline \multicolumn{4}{|c|}{ Right hand } \\
\hline $\begin{array}{l}\text { Median nerve: } \\
\operatorname{MCV}(\mathrm{m} / \mathrm{s}) \\
\operatorname{DL}(\mathrm{ms}) \\
\operatorname{SCV}(\mathrm{m} / \mathrm{s})\end{array}$ & $\begin{array}{c}51 \cdot 5 \pm 3 \cdot 3^{\star \star} \\
4 \cdot 4 \pm 0 \cdot 4^{\star \star \star} \\
36 \cdot 4 \pm 6 \cdot 2^{\star \star \star 2}\end{array}$ & $\begin{array}{r}54 \cdot 2 \pm 4 \cdot 0 \\
3 \cdot 8 \pm 0 \cdot 4 \\
48 \cdot 2 \pm 4 \cdot 5^{1}\end{array}$ & $\begin{array}{l}3 \cdot 0129 \\
6 \cdot 8065 \\
5 \cdot 7422\end{array}$ \\
\hline $\begin{array}{l}\text { Ulnar nerve: } \\
\operatorname{MCV}(\mathrm{m} / \mathrm{s}) \\
\operatorname{DL}(\mathrm{ms}) \\
\operatorname{SCV}(\mathrm{m} / \mathrm{s})\end{array}$ & $\begin{array}{c}52 \cdot 5 \pm 4 \cdot 4^{\star \star} \\
4 \cdot 4 \pm 0 \cdot 5 \\
47 \cdot 1 \pm 4 \cdot 4^{4}\end{array}$ & $\begin{array}{r}55 \cdot 2 \pm 4 \cdot 0 \\
4 \cdot 2 \pm 0 \cdot 4 \\
48 \cdot 3 \pm 4 \cdot 5^{3}\end{array}$ & $\begin{array}{l}2.8563 \\
1.3019 \\
0.9695\end{array}$ \\
\hline \multicolumn{4}{|c|}{ Left hand } \\
\hline $\begin{array}{l}\text { Median nerve: } \\
\operatorname{MCV}(\mathrm{m} / \mathrm{s}) \\
\operatorname{DL}(\mathrm{ms}) \\
\operatorname{SCV}(\mathrm{m} / \mathrm{s})\end{array}$ & $\begin{array}{c}53 \cdot 7 \pm 5 \cdot 0 \\
4 \cdot 4 \pm 0 \cdot 7 \star \star \star \\
41 \cdot 9 \pm 7 \cdot 1^{6}\end{array}$ & $\begin{array}{c}54 \cdot 8 \pm 4 \cdot 3 \\
3.9 \pm 0.5 \\
45 \cdot 9 \pm 4.9^{5}\end{array}$ & $\begin{array}{l}1.0951 \\
4.4235 \\
2.8974\end{array}$ \\
\hline $\begin{array}{l}\text { Ulnar nerve: } \\
\operatorname{MCV}(\mathrm{m} / \mathrm{s}) \\
\operatorname{DL}(\mathrm{ms}) \\
\operatorname{SCV}(\mathrm{m} / \mathrm{s})\end{array}$ & $\begin{array}{c}55 \cdot 1 \pm 3 \cdot 6 \\
4 \cdot 6 \pm 0 \cdot 5^{\star} \\
48 \cdot 8 \pm 3 \cdot 5^{8}\end{array}$ & $\begin{array}{c}56 \cdot 5 \pm 4 \cdot 2 \\
4 \cdot 4 \pm 0 \cdot 4 \\
49 \cdot 0 \pm 3 \cdot 9^{7}\end{array}$ & $\begin{array}{l}1.5395 \\
2.1169 \\
0.2559\end{array}$ \\
\hline
\end{tabular}

clinical examination, and EMG findings together. A useful screening method is the determination of the vibrotactile perception threshold. ${ }^{16}{ }^{17}$ The risk arising from a small carpal canal may be shown by computerised tomography and this may help with idiopathic CTS. ${ }^{18}$ In subclinical CTS there are nocturnal, short lasting paraesthesias, ${ }^{7}$ tingling in the fingers innervated by the median nerve, but no EMG findings. Buchthal et al reported difficulties in the electro-physiological diagnosis of CTS and this emphasises why a diagnosis of CTS must be based on clinical verification. ${ }^{19}$

In the present study we found an association of CTS with forestry work. Twenty five of 125 forestry workers had a neurological history, clinical findings, and EMG findings compatible with CTS. A high prevalence of CTS has been reported by other authors. ${ }^{90}$ Ahlborg and Voogt reported in their casecontrol study of CTS that heavy manual work increased the risk of CTS by a factor of two, and when combined with hand-arm vibration the risk increased by a factor of five. ${ }^{9}$ Exceptionally heavy manual work with simultaneous exposure to vibration could increase the risk of CTS by a factor of ten. Chatterjee et al examined 16 rock drillers and 15 controls and found a prevalence of possible CTS of $44^{\circ}{ }_{0}$ compared with $7 \%$ in the controls. ${ }^{20}$

Symptoms of CTS in the present study were similar to those that have been considered as typical of the neuropathies. ${ }^{15}$ Juntunen and his coworkers have reported a high prevalence $(40-60 \%)$ of non- specific peripheral neuropathy among forestry workers. ${ }^{2}$ Seppäläinen found vibration induced neuropathy frequently in both ulnar and median nerves at the same time and she interpreted the EMG results to be indicative of diffuse damage to the myelin sheath and disregarded CTS as a possible explanation. ${ }^{1}$ Buchthal et al in their investigation of patients with CTS and compression syndrome of the median nerve at the elbow found that $15 \%$ of patients had clinical and electrophysiological signs of an ulnar nerve lesion in addition to CTS. ${ }^{19}$ According to their study a simultaneous ulnar nerve lesion does not exclude a CTS.

\section{AETIOLOGICAL FACTORS}

The aetiology of peripheral nerve damage in forestry workers is multifactorial. Static muscle forces may retard the circulation of the fine nerve filaments and nerve trunks. Dynamic muscle force may cause hypertrophy of the finger flexors. Silverstein et al found that heavy manual force combined with high repetitiveness gave more than an additive risk for CTS. ${ }^{11}$ The risk of CTS increased more than five times than that of either factor alone in this study. Vibration was also an important risk factor for CTS.

The left hand is the dominant working hand in sawing, the right hand acting more to direct the saw during the operation. The vibration level in the hands is directly proportional to the cube root of the grip force. ${ }^{2122}$ The vibration level is about twice as high in the right hand than in the left but the grip force is greater in the left hand, which increases the transmission of the vibration into the left hand. Thus there are factors enough to cause the symptoms of CTS in both hands.

The ulnar nerve is anatomically more superficial, unsheltered by muscles, and has more stretch during sawing than the median nerve. Therefore, it is also liable to damage in forestry work. In the present study exposure to vibration correlated significantly with motor NCV in the ulnar nerve of the left hand. Seppäläinen has also observed decreased conduction velocities in the ulnar nerve in men with exposure to vibration. ${ }^{1}$

\section{MECHANISM OF NERVE DAMAGE}

The mechanism of nerve damage is not known. Oedema of the wrist tissues (connective and intraneural tissues) after exposure to vibration may cause some of the symptoms. Lundborg et al have shown in their experimental study of rats that chronic exposure to vibration induces oedema in the nerve. ${ }^{7}$ Because of the stiffness of the perineurium the nerve cannot expand and this will lead to increased intraneural pressure which causes venous congestion and retards the microcirculation within the nerve. The situation is reversible and symptoms appear in the beginning mainly at night when the arterial pressure 
and venous congestion are raised in the recumbent position. When exposure leads to chronic swelling the changes will lead also to permanent nerve compression. This may cause diffuse degeneration in the nerve and corresponding EMG changes.

Chain saw operation entails static and dynamic muscle work that may cause hypertrophy of the synovial tissue of the finger flexors as $\mathrm{Phalen}^{23}$ and Falck and Aarnio $^{24}$ have proposed. This may aggravate the entrapment on the median nerve in the carpal tunnel as well as oedema of the perineural tissue. ${ }^{725}$ This vibration induced entrapment may be diffuse and affect nerves other than the median.

\section{NEUROPHYSIOLOGICAL MEASUREMENTS AND CTS}

Measurements of the sensory and motor conduction velocity of the peripheral nerves have been used to estimate nerve injury. EMG is, however, nonspecific and because of this and the wide spread of normative values, ${ }^{20}$ some researchers are cautious in interpreting the results of nerve conduction velocity measurements.

In Seppäläinen's study the distal latencies were longer than we observed. ' Today, many of those workers still have diminished conduction velocities but no symptoms of CTS. During the past 20 years there has been a considerable change in forestry work. Chain saws have become lighter and vibrate less. ${ }^{1326}$ The old tools may have provoked CTS to a much greater extent than those used now. Presumably, because of chronic nerve compression, the retarded NCVs derive from the period with heavier saws, and symptoms have subsided, although NCVs remain lowered. The incidence of symptoms of vibration induced neuropathy has decreased in concordance with lighter, less vibrating saws. ${ }^{4}$

\section{VIBROTACTILE THRESHOLD}

The determination of the vibrotactile perception threshold has been used in assessing the severity of peripheral neuropathy. ${ }^{2728}$ Some investigators, however, have experienced difficulties in interpreting the results of this test. ${ }^{29}$ There is a big overlap in the threshold values obtained from disabled and symptom free subjects. The neurological findings in the clinical evaluation in one study were not associated with an increased vibrotactile threshold in forestry workers. ${ }^{29}$ Other investigators consider vibrotactile threshold detection as an important tool in assessing the severity of the peripheral nervous system and in carefully screened subjects find a good correlation with vibrotactile perception threshold shift and vibration induced neuropathy and with vibration induced white finger. ${ }^{7}$

Vibration perception is disturbed in $\mathrm{CTS}^{16}$ but similar vibrotactile thresholds have been found among forestry workers with and without vibration induced neuropathy or peripheral vascular distur- bances. ${ }^{1315}$ Assessing a vibrotactile detection threshold causes the same difficulties as with nerve conduction studies: a lack of the specificity of the finding. A reduced vibrotactile sensitivity is typically found also in CTS and occurs at the same frequencies as vibration induced neuropathy. ${ }^{15}$

Requests for reprints to: Dr Kaija Koskimies, Institute of Occupational Health, Haartmaninkatu 1, SF-00290 Helsinki.

1 Seppäläinen A-M. Peripheral neuropathy in forest workers: a field study. Work Environmental Health 1972;9:106-11.

2 Juntunen J, Matikainen E, Seppäläinen A-M, Laine A. Peripheral neuropathy and vibration syndrome. Int Arch Occup Environ Health 1983;4:17-24.

3 Färkkilä M. Grip force in vibration disease. Scand J Work Environ Health 1978;4:159-66.

4 Pyykkö I, Sairanen E, Korhonen O, Färkkilä M, Hyvärinen J. A decrease in the prevalence and severity of vibration induced white fingers among lumberjacks in Finland. Scand $J$ Work Environ Health 1978;4:246-54.

5 Marshall J, Poole EB, Reynard WA. Raynaud's phenomenon due to vibrating tools. Lancet 1954;i:1151-6.

6 Taylor W, Pelmear PL, Pearson J. Raynaud's phenomenon in forestry chain saw operators. In: Taylor $\mathrm{W}$, ed. The vibration syndrome. London: Academic Press, 1974:121-39.

7 Lundborg G, Dahlin LB, Hansson HA, Pyykkö I. Intraneural oedema following exposure to vibration. Scand $J$ Work Environ Health 1987;13:(suppl):326-9.

8 Lucas E. Peripheral nervous system and hand arm vibration. In: Brammer AJ, Taylor W, eds. Vibration effects on the hand arm in industry. New York: John Wiley, 1982:39-43.

9 Ahlborg G, Voog L. Vibration exposure and distal compression of the median nerve ("carpal tunnel syndrome"). Läkartidningen 1982;79:4905-8.

10 Armstrong TJ, Fine LJ, Silverstein BA. Occupational risk factors, cumulative trauma disorders of the hand and wrist. (NIOSH contract 200-82-2507.) Michigan: University of Michigan, 1985.

11 Silverstein B, Fine LJ, Armstrong TJ. Carpal tunnel syndrome. Causes and preventive strategy. Seminars in Occupational Medicine 1986;3:213-21.

12 Pyykkö I. The prevalence and symptoms of traumatic vasospastic disease among lumberjacks in Finland. A field study. Work Environmental Health 1974;11:1-14.

13 Pyykkö I, Korhonen O, Färkkilä M, Starck J, Aatola, S, Jäntti V. Vibration syndrome among Finnish forest workers, a followup from 1972 to 1983 . Scand J Work Environ Health 1986;12:307-12.

14 Déllon AL. Clinical use of vibratory stimuli to evaluate peripheral nerve injury and compression neuropathy. Plast Reconstr Surg 1980;15:466-70.

15 Färkkilä M, Aatola S, Starck J, Pyykkö I, Korhonen O. Vibration induced neuropathy among forestry workers. Acta Neurol Scand 1985;71:221-5.

16 Blecker ML. Vibration perception thresholds in entrapment and toxic neuropathies. J Occup Med 1986;28:991-4.

17 Lundborg G, Solleman CH, Strömberg T, Pyykkö I, Rosen B. A new principle for assessment of vibrotactile sense in vibration induced neuropathy. Scand J Work Environ Health 1987; 13suppl:375-9.

18 Bleeker ML, Agnew J. New technics for the diagnosis of carpal tunnel syndrome. Scand J Work Environ Health 1987;13: 385-8.

19 Buchthal F, Rosenfalck A, Trojaborg W. Electrophysiological findings in entrapment of the median nerve at the wrist and elbow. J Neurol Neurosurg Psychiatry 1974;37:340-60.

20 Chatterjee DS, Barrwick DD, Bertrie A. Exploratory electromyography in the study of vibration-induced white finger in rock drillers. $\mathrm{Br} J$ Ind Med 1982;39:89-97.

21 Hempstock TI, O'Connor DE. The vibration characteristics of several engineering processes which produce white fingers. In: Taylor W, ed. The vibration syndrome. London: Academic Press, 1974:51-60. 
22 Pyykkö I, Färkkilä M, Toivanen J, Korhonen O, Hyvärinen J. Transmission of vibration in the hand-arm system with special reference to changes in compression force and acceleration. Scand J Work Environ Health 1976;2:87-95.

23 Phalen GS. The carpal tunnel syndrome. Clin Orthop 1972; 83:29-40.

24 Falck B, Aarnio P. Left-sided carpal tunnel syndrome in butchers. Scand J Work Environ Health 1983;9:291-7.

25 Färkkilä M. Vibration induced injuries. $B r J$ Ind Med 1986; 43:361-2.

26 Starck J. Characteristics of vibration, hand grip force, and hearing loss in vibration syndrome. (University of Kuopio, Natural Sciences, original reports 4/1984.) Kuopio: Emanuelson, 1984.

27 Johansson RS, Wallbo AB. Detection of tactile stimuli.
Thresholds of afferent units related to psychophysical thresholds in the human hand. J Physiol (London) 1979; 297:405-22.

28 Johansson RS, Wallbo AB. Spatial properties of the population of mechanoreceptive units in the glabrous skin of the human hand. Brain Res 1980;184:353-66.

29 Aatola S, Starck J, Pyykkö I, Färkkilä M, Korhonen O. Vibration detection threshold of lumberjacks. In: Proceeding of the international symposium on the protection of workers against vibration. Niš, Yugoslavia. (Organization Committee of the Institute for Occupational Safety and Health Documentation.) Niš: Edward Kardellju, 1982:347-51.

Accepted 7 August 1989

\section{Spittoons}

Prevention of the spread of infection is of undoubted importance. Notices are frequently displayed commanding persons not to spit. The intention of these notices is admirable, but personal observation makes manifest to all that they do not effect their purpose. Even if the rising generation adopt better manners and do not acquire the habit of expectorating (of which we can at present see no obvious signs), the present generation possess the habit, which must be dealt with as an existing custom-an objectionable thing which may be ameliorated before it is abolished. Few persons unacquainted with industry can be aware of the danger to the public as well as to the workers themselves arising from spitting. When, however, we state that expectoration takes place into tea, dough troughs, fish, vegetables and other comestibles, as well as upon materials used for wearing apparel, the necessity for action becomes clearer.

The provision of spittoons or cuspidors is the only practical remedy. Working men are accustomed to their use in inn-parlours, and can be persuaded to use them. Spittoons should be placed in readily access- ible positions-not on the floor where they are readily knocked over. They should be made of enamelled metal with long handles for convenience of removal. Every day they should be washed out with hot water and exposed to a jet of steam during five to ten minutes.

The provision of spittoons is of value for the control, not only of tubercular infection, but of the more frequent catarrhal infections. The main objection to dry sweeping of floors rests upon the presence there of dried sputa; if all spitting was into spittoons, floor dust would be come less infectious. While the provision and proper use of spittoons would go far to minimise the danger arising from spitting, a new custom would thereby be introduced. Workers, like others, are naturally conservative and might readily object, and a manager would be well advised to place the matter in the hands of the welfare committee of the works. If this committee decide in favour of spittoons, they will ensure that promiscuous spitting no longer takes place.

(From The Health of the Industrial Worker by E L Collis and M Green published by Churchill in 1921.)

J A LUNN 